\title{
EVALUATION OF THE POSSIBILITY OF USING THE PREDICTED TROPOSPHERIC DELAYS IN REAL TIME GNSS POSITIONING
}

\author{
J. Z. Kalita ${ }^{1)}$, Z. Rzepecka ${ }^{2)}$, G. Krzan ${ }^{2)}$ \\ ${ }^{1)}$ Department of Civil Engineering, Environmental Engineering and Geodesy, \\ Koszalin University of Technology \\ ${ }^{2)}$ Institute of Geodesy, University of Warmia and Mazury in Olsztyn \\ e-mails: jakub.kalita@tu.koszalin.pl, zofia.rzepecka@uwm.edu.pl,grzegorz.krzan@uwm.edu.pl
}

\begin{abstract}
Among many sources of errors that influence Global Navigation Satellite System (GNSS) observations, tropospheric delay is one of the most significant. It causes nonrefractive systematic bias in the observations on the level of several meters, depending on the atmospheric conditions. Tropospheric delay modelling plays an important role in precise positioning. The current models use numerical weather data for precise estimation of the parameters that are provided as a part of the Global Geodetic Observation System (GGOS). The purpose of this paper is to analyze the tropospheric data provided by the GGOS Atmosphere Service conducted by the Vienna University of Technology. There are predicted and final delay data available at the Service. In real time tasks, only the predicted values can be used. Thus it is very useful to study accuracy of the forecast delays. Comparison of data sets based on predicted and real weather models allows for conclusions concerning possibility of using the former for real time positioning applications. The predicted values of the dry tropospheric delay component, both zenith and mapped, can be safely used in real time PPP applications, but on the other hand, while using the wet predicted values, one should be very careful.
\end{abstract}

Keywords: tropospheric delay, Vienna Mapping Function, troposphere prediction.

\section{INTRODUCTION}

Troposphere, primarily composed of nitrogen and oxygen, is the lowest layer of the atmosphere. This non dispersive medium affects the electromagnetic signals so it is necessary to reduce delays in radio signals reception in precise GNSS applications. In recent years troposphere mapping functions based on data from numerical weather models have been used to improve the accuracy of satellite geodetic observations analysis (Nilson et al., 2013).

The tropospheric delay is a function of the refracting index, dependent on the local temperature, pressure and relative humidity. It can be separated into two componentshydrostatic and wet (Davis et al., 1985). In addition, slant delay is typically separated into zenith delay and the mapping function. The zenith hydrostatic delay, caused by the dry atmosphere, is proportional to atmospheric pressure at the site. It ranges from 1.5 to $2.6 \mathrm{~m}$ and thus comprises about $90 \%$ of the total zenith delay (Jin et al., 2007). The zenith wet delay is more difficult to deal with, due to irregular distribution of the water vapour in the atmosphere (Leick, 1994). It comprises about $10 \%$ of the total zenith delay and it is highly unstable, ranging from 0 to $30 \mathrm{~cm}$. It is related to the amount of water vapor and the temperature along the signal track. Most of the zenith total delay seasonal variation is mainly 
due to the wet part (Jin et al., 2007). This part can be either mitigated by means of relative GNSS positioning or estimated as an additional parameter during the processing. Example annual distribution of tropospheric dry and wet zenith delay for single location is presented in Figure 1. The impact of the troposphere on the GNSS observations intensifies with the increase of the zenith angle.
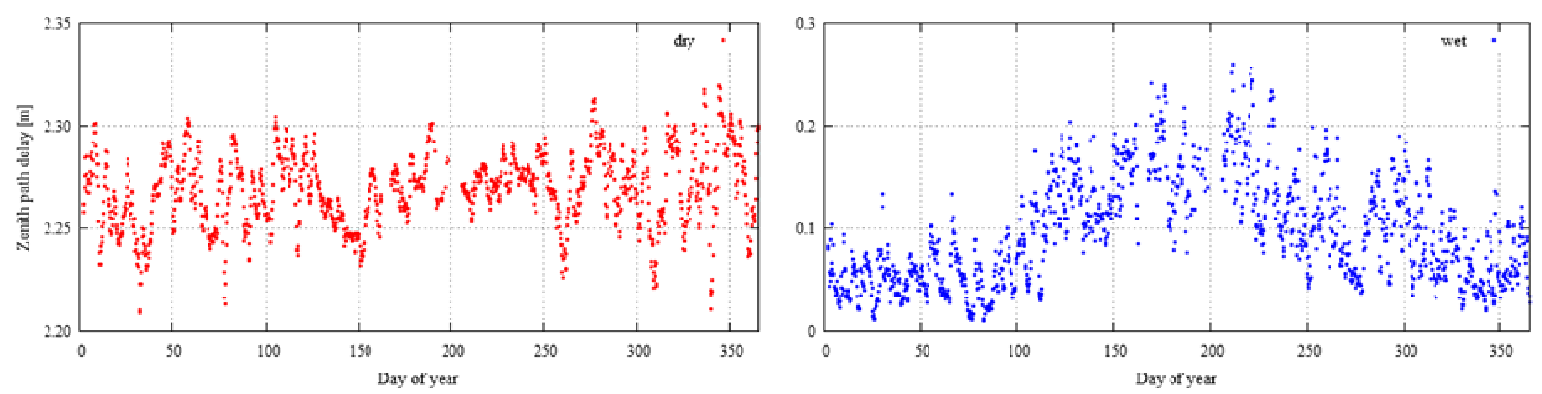

Fig. 1. Zenith path delay for hydrostatic (a) and wet (b) components for selected grid

$$
\text { cell } \varphi \in\left(52^{\circ}-54^{\circ}\right) ; \lambda \in\left(20^{\circ}-22.5^{\circ}\right)
$$

The Eqn. 1 illustrates the total tropospheric delay $\Delta L(e)$ at elevation angle $e$. Hydrostatic and wet parts are made up of the zenith delay $\left(\Delta L_{h}^{Z}\right)$ or $\left(\Delta L_{w}^{Z}\right)$ and corresponding mapping function $m f_{h}(e)$ or $m f_{w}(e)$ (Böhm et al., 2006):

$$
\Delta L(e)=\Delta L_{h}^{Z} \cdot m f_{h}(e)+\Delta L_{w}^{Z} \cdot m f_{w}(e)
$$

The Vienna Mapping function (VMF), currently the most accurate mapping function for geodetic applications (Urquhart et al., 2013), was introduced by Böhm and Schuh (2004). It bases on Eqn. 2 with the hydrostatic and wet parts determined separately by fitting the coefficients $a, b$ and $c$ of a continued fraction form (Marini et al. 1972) and normalized to yield unity at zenith (Herring, 1992):

$$
m f(e)=\frac{1+\frac{\mathrm{a}}{1+\frac{\mathrm{b}}{1+\mathrm{c}}}}{\sin e+\frac{\mathrm{a}}{\sin e+\frac{\mathrm{b}}{\sin e+\mathrm{c}}}}
$$

The above type of mapping function, dependent on elevation angle, has been developed during the last decades by Ifadis (1986), Herring (1992), Niell (1996). These mapping functions, apart from different representations, differ in parameterizations of the coefficients $\mathrm{a}, \mathrm{b}$ and $\mathrm{c}$.

The updated version of VMF (VMF1) relies on empirical equations for the $b$ and $c$ coefficients of the Eqn. 2 (Böhm, 2006), whereas the a coefficients are determined from rigorously ray-traced mapping functions at 3 degrees elevation. When determined, the $b$ coefficient remains a constant value, whereas $\mathrm{c}$ is dependent on the hemisphere (N or $\mathrm{S})$, latitude and the day of year.

The VMF1 data is provided on a global grid $\left(2.5^{\circ} \times 2.0^{\circ}\right)$ as well as at selected sites with a resolution of $0.25^{\circ}$ (Böhm et al. 2007). The four coefficients: $\Delta L_{h}^{Z}, \Delta L_{w}^{Z}$ and a for hydrostatic $\left(a_{h}\right)$ and wet $\left(a_{w}\right)$ part are determined from global analysis of data at the European Centre for Medium-Range Weather Forecast (ECMWF). Data from ECMWF include levelled (60 levels with $85 \mathrm{~km}$ altitude at the top level) meteorological parameters such as pressure, temperature 
and relative humidity. The ground parameters include pressure and dew temperature at 2 meters (Chen, 2012). The grids from VMF services are provided at 0, 6, 12 and $18 \mathrm{UT}$ and are available at $23 \mathrm{~h} \mathrm{UT}$ the next day (Böhm et al. 2008).

Despite the wide variety of applications of VMF service in tasks involving the postprocessing of observations, it is not possible to use final products in real-time applications. For these purposes it is possible to use the gridded coefficients derived from forecasting data of the EMCWF which are available at the same time intervals as actual (real, final) parameters for the following day.

The purpose of this work is to analyse the errors in tropospheric predictions in context of real-time precise GNSS positioning. In the analysis, estimation of hydrostatic component of the zenith delay together with mapping coefficient influence on the final height is performed. In addition, quality of wet component prediction is also verified.

\section{METHODOLOGY}

The main aim of this paper is to analyse differences between the predicted and final tropospheric delays. Comparisons were performed directly using values available at the service (http://ggosatm.hg.tuwien.ac.at/DELAY/). Gridded data were used. Table 1 presents example delay data as available at the Service. The analyses were carried out for the whole year 2013, with four epochs during each day $(0,6,12,18 \mathrm{UT})$. The respective forecast period is 24, 30, 36 and 42 hours (Böhm et al., 2008). The one year period was chosen as a representative time span since most of the power distribution for the troposphere spectrum is contained in it (Jin et al., 2007). For the tropospheric grid data available at the service, data from 75 of 1460 of the epochs were missing or contained errors. Either the whole file was missing or contained some binary noise instead of text. The period when the most of the epochs are missing is June and July, between the days 163 and 205.

Table 1. Beginning of the file VMFG_20130102.H00 (at: http://ggosatm.hg.tuwien.ac.at/)

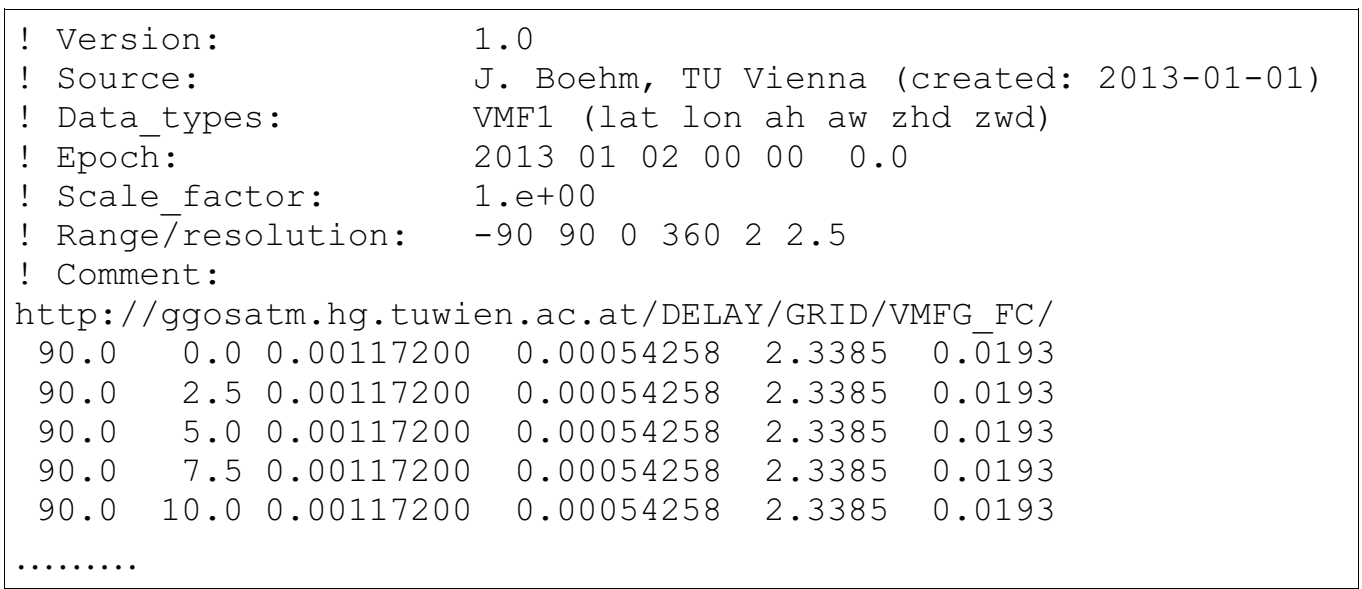

Threefold comparisons were performed: for a single chosen cell of the grid, for the region of Central Europe and for the whole world. Treating the final values as a reference, the predicted values quality was assessed.

In the first case, the cell of $\left[\varphi \in\left(52^{\circ}-54^{\circ} N\right) ; \lambda \in\left(20^{\circ}-22.5^{\circ} E\right)\right]$ was selected (the LAMA IGS station is located in it). The analyses are most detailed here. The comparisons concerned not only the zenith dry and wet delays, but also the $a_{h}$ and $a_{w}$ coefficients, used in mapping procedure (see Eqn. 2). In addition, slant delays mapped to several elevation angles including $5^{\circ}$ and $15^{\circ}$ using the VMF1 mapping function with coefficients obtained from the service were compared and analysed. 
In the second case, the analyses comprised gridded data from an area for $\left[\varphi \in\left(48^{\circ}-56^{\circ} N\right) ; \lambda \in\left(12.5^{\circ}-25^{\circ} E\right)\right]$, which corresponds to the region of Central Europe and contains the territory of Poland (see Fig. 5). This area consists of 30 cells. For each cell the differences between the predicted and final delays were computed, independently for the dry and wet components. Basic statistics, like minimum, maximum, mean and standard deviations of the determined differences were computed and analysed.

In the third case analysis was done for global set of grid data covering the whole Earth, based on four selected epochs (February, May, August and November). As before, the predicted and final hydrostatic and wet delays were compared against each other.

\section{RESULTS}

In the description of results the division of studies given in the methodology sections is maintained, thus the results for an individual cell (3.1), for Central Europe (3.2) and for the whole world (3.3) are presented below.

\subsection{INDIVIDUAL CELL COMPARISONS}

Let us start with presenting the direct differences between the hydrostatic and wet components of the predicted and final tropospheric zenith delays. The differences are given in Fig. 2. The histograms of the differences are presented in Fig. 3. The characteristics are typical for the analysed area. Hydrostatic zenith delay rarely exceeds the threshold of $5 \mathrm{~mm}$. Looking at the histogram it can be seen that almost 1000 of about 1500 differences fall within the interval -2 to $2 \mathrm{~mm}$. In about 20 cases the differences are less than $-5 \mathrm{~mm}$ or bigger than 5 $\mathrm{mm}$. With most of the values within the $2-3 \mathrm{~mm}$ distance from 0 the statement, that the predicted dry zenith estimation is of good quality, can be confirmed. No significant change in the variability during the year can be observed.
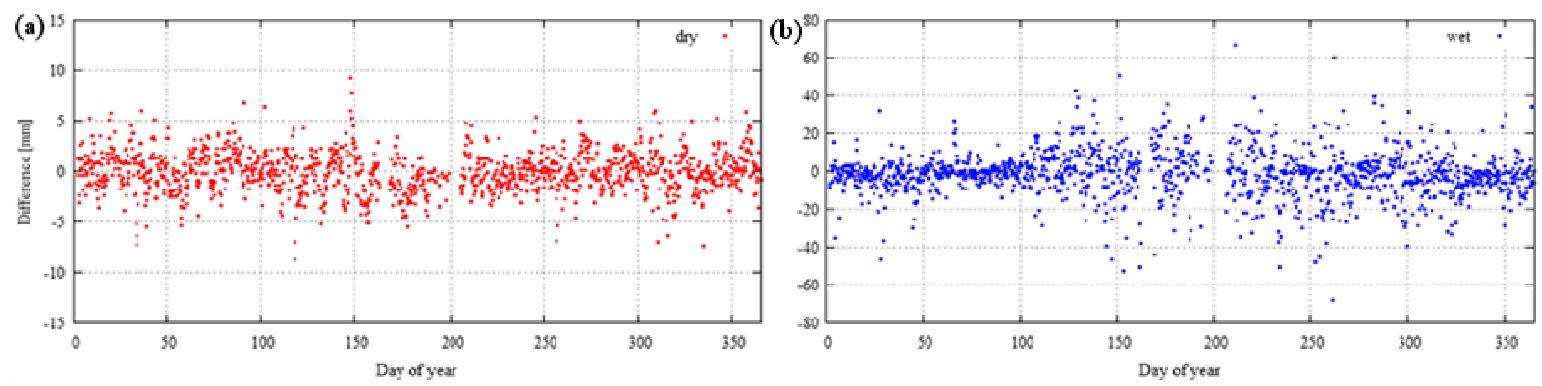

Fig. 2. The comparison of hydrostatic (a) and wet (b) components for the selected grid cell $\varphi \in\left(52^{\circ}-54^{\circ}\right) ; \lambda \in\left(20^{\circ}-22.5^{\circ}\right)$
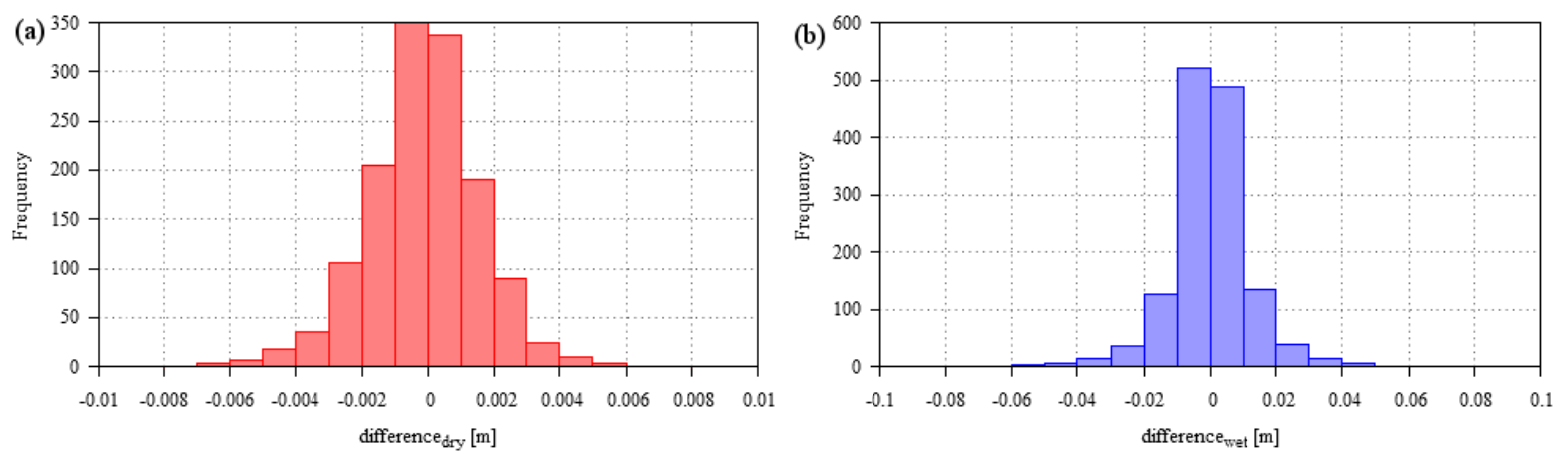

Fig. 3. Histograms of differences distributions for the dry (a) and wet (b) components; the resolution of allocation is $1 \mathrm{~mm}$ for dry and $1 \mathrm{~cm}$ for wet differences. 
However, the differences can vary during the day and thus in the area of real-time GNSS positioning, it is worthwhile to analyse each of the epochs separately instead of performing daily aggregation for which most of the daily mean values is inside the $+/-2 \mathrm{~mm}$ area around 0 with single points exceeding $5 \mathrm{~mm}$. The variability of the prediction errors increases during the day. For hydrostatic component the standard deviation for hours 0-6 deteriotates by about $30 \%$ comparing to hours $18-24$. This may be caused by the longer prediction periods for later hours during the day.

The most (about 1250 per 1500 of all the data) of the wet component of the forecast error is located in $20 \mathrm{~mm}$ area around zero. Less than 10 differences are outside the region of $\pm 5 \mathrm{~cm}$ around zero. The standard deviation varies across the year. The variation correlates well with the amplitudes of the wet zenith path delay (see Fig. 1). Up to about half of March (day number 100) the error almost does not exceed $10 \mathrm{~mm}$ with the $\mathrm{z}_{\mathrm{w}}$ being below $10 \mathrm{~cm}$. Afterwards the error increases about twice with the $z_{w}$ values reaching up to about $25 \mathrm{~cm}$. The wet component error varies during the day. The standard deviation value from the whole year deteriotates from hour $0-6$ to $18-24$ by $40 \%$ of the former. Again probable reason for this is the longer prediction period at later hours.

Table 2. Minimum, maximum, mean and standard deviation values of the prediction error for selected grid cell

\begin{tabular}{ccccccccc}
\hline & \multicolumn{2}{c}{ a } & \multicolumn{2}{c}{ zenith } & \multicolumn{2}{c}{$5^{\circ}$ elevation } & \multicolumn{2}{c}{$15^{\circ}$ elevation } \\
& $\begin{array}{c}\text { dry }\left[\times 10^{-}\right. \\
5]\end{array}$ & $\begin{array}{c}\text { wet }\left[\times 10^{-}\right. \\
\left.{ }^{4}\right]\end{array}$ & $\begin{array}{c}\text { dry } \\
{[\mathrm{cm}]}\end{array}$ & $\begin{array}{c}\text { wet } \\
{[\mathrm{cm}]}\end{array}$ & $\begin{array}{c}\text { dry } \\
{[\mathrm{cm}]}\end{array}$ & $\begin{array}{c}\text { wet } \\
{[\mathrm{cm}]}\end{array}$ & $\begin{array}{c}\text { dry } \\
{[\mathrm{cm}]}\end{array}$ & $\begin{array}{c}\text { wet } \\
{[\mathrm{cm}]}\end{array}$ \\
\hline Minimum & -0.36 & -1.20 & -0.9 & -6.8 & -9.5 & -71.7 & -3.3 & -25.9 \\
Maximum & 0.66 & 1.45 & 0.9 & 6.7 & 10.1 & 71.2 & -3.6 & 25.6 \\
$\begin{array}{c}\text { Mean } \\
\text { Standard }\end{array}$ & 0.02 & 0.00 & 0 & 0.1 & -0.1 & -1.5 & 0 & -0.5 \\
deviation & 0.08 & 0.22 & 0.2 & 1.2 & 2.1 & 12.9 & 0.8 & 4.6 \\
\hline
\end{tabular}

The statistics for the entire analyzed period and single grid cell are presented in Table 2. The standard deviation and mean values of the parameters are similar to those calculated basing on all analyzed grid points and thus the cell was assumed representative. Standard deviation of the forecast error amounts to about $2 \mathrm{~mm}$ for the zenith hydrostatic component. Maximum error values reach $9 \mathrm{~mm}$ (for all grid cells they reach $14 \mathrm{~mm}$ ).

According to Böhm et al. (2006) the delay error due to mapping it to $5^{\circ}$ elevation with the wrong mapping function coefficients (wet) is the 0.6 of the $\mathrm{z}_{\mathrm{h}}$ (based on assumption: $\mathrm{Z}_{\mathrm{h}}=2000 \mathrm{~mm}$ and $\mathrm{zW}=200 \mathrm{~mm}$ ), thus the maximum error value of $9 \mathrm{~mm}$ introduces $5.4 \mathrm{~mm}$ error for $5^{\circ}$ elevation. The propagation of the error to resulting station height is one fifth of the error at $5^{\circ}$ elevation. This gives maximum error value of about $1 \mathrm{~mm}$ due to using $\mathrm{z}_{\mathrm{h}}$ forecast data and thus hydrostatic zenith delay prediction is of good quality in frames of realtime GNSS positioning.

To assess the mapping function error due to error in a coefficient the latter is multiplied by 1000 (Böhm et al., 2008; the rule of thumb A2 and A3). Maximal value of error in $a_{h}$ gives about $7 \mathrm{~mm}$ of mapping error at $5^{\circ}$ elevation. This results in about $1.3 \mathrm{~mm}$ of maximal error in result height due to error in $a_{h}$ forecast for the whole year. For the wet component the quality is much worse. The analogous $5^{\circ}$ elevation maximal error would be about $15 \mathrm{~cm}$. Performing the similar simplification on standard deviations errors of $1 \mathrm{~mm}$ and $22 \mathrm{~mm}$ are received for $5^{\circ}$ elevation of dry and wet components respectively. 

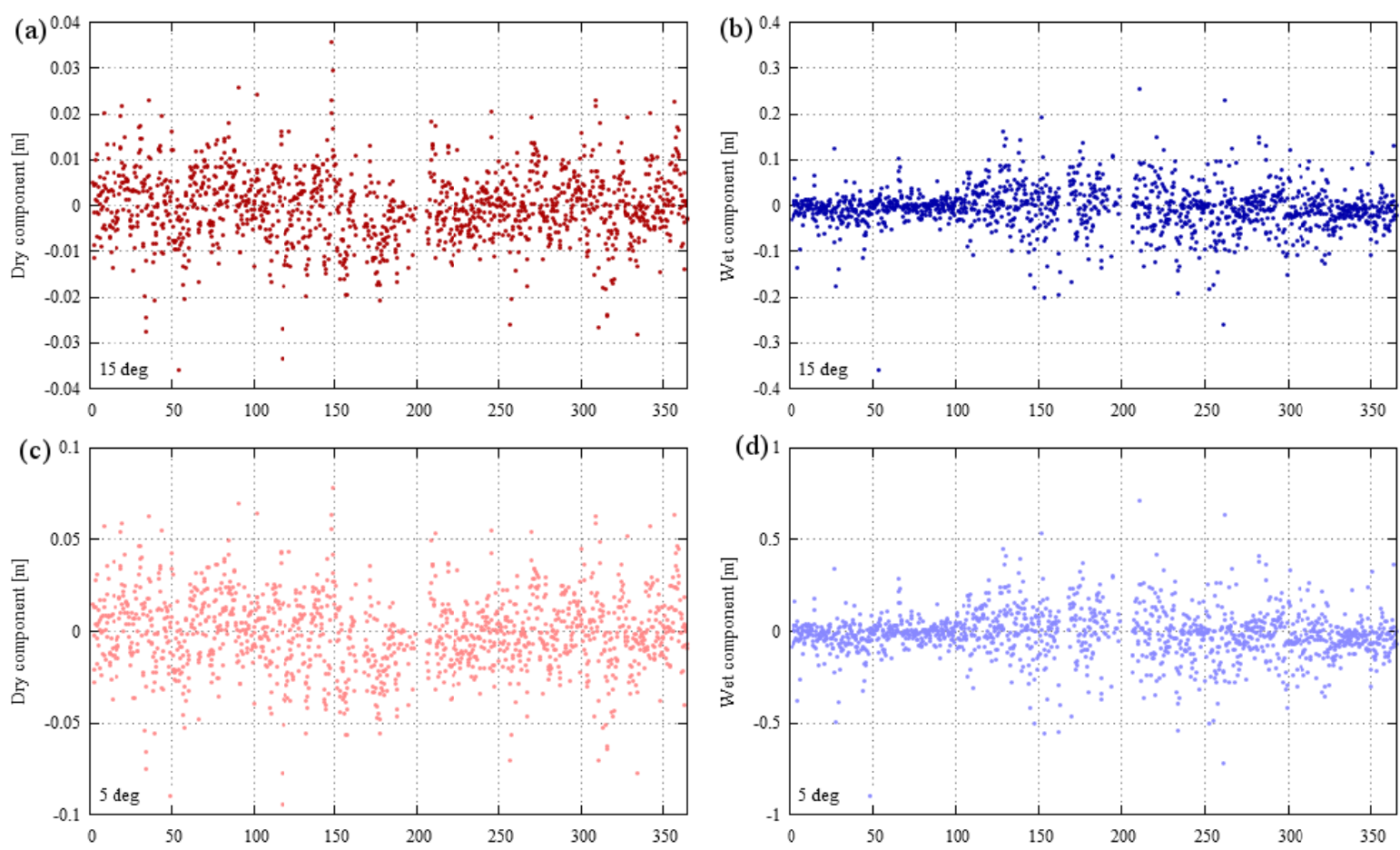

Fig. 4. Slant delay error for dry $(\mathrm{a}, \mathrm{c})$ and wet $(\mathrm{b}, \mathrm{d})$ components at $5^{\circ}$ and $15^{\circ}$ elevation respectively for the cell $\varphi \in\left(52^{\circ}-54^{\circ}\right) ; \lambda \in\left(20^{\circ}-22.5^{\circ}\right)$.

In addition to comparing the $\mathrm{a}_{\mathrm{h}}$ and $\mathrm{a}_{\mathrm{w}}$ coefficients available at the service (see Table 2), the VMF1 mapping was performed using the procedure vmfl_ht (available at the Service) with forecast and real coefficients. This enabled analysis of slant delays errors at several elevations including $5^{\circ}$ and $15^{\circ}$ (see Fig. 4). This analysis cumulates the zenith delay error and the error for the $a_{h}$ and $a_{w}$ coefficients. The respective standard deviations are 2.1 and $12.9 \mathrm{~cm}$ for dry and wet components. Part of the dry error will be included in estimated wet delay.

\subsection{COMPARISONS FOR THE REGION OF CENTRAL EUROPE}

The differences obtained for an individual chosen cell, are representative for the whole region of Central Europe, but yet some additional findings were observed. When analysing the spatial distribution of zenith delay errors in the analysed area (see Fig. 5) an underestimation of forecast delays for dry and wet components can be noticed. In the Fig. 5 all the values are given in millimeters. The circles contain basic statistical description for the differences between the predicted and final delays. The left and right circles concern the hydrostatic and wet components data respectively. The values from the top to the bottom of the circle are as follows: minimum (red) and maximum (blue) difference for the cell during the year 2013, the mean value of the difference for the whole year for that cell (green), and at the very bottom the standard deviations of the differences (magenta).

The mean for most of the grid cells is on the level of about $0.2 \mathrm{~mm}$ and $1 \mathrm{~mm}$ for dry and wet components respectively. The standard deviation of dry component error is positively correlated with latitude. Respective differences in extreme values for dry and wet components between the cells in the analyzed area reach $1 \mathrm{~cm}$ and $5-9 \mathrm{~cm}$. The discrepancy in predicted data rarely exceeds $1.5 \mathrm{~mm}$ and $1.5 \mathrm{~cm}$ for dry and wet components respectively. 


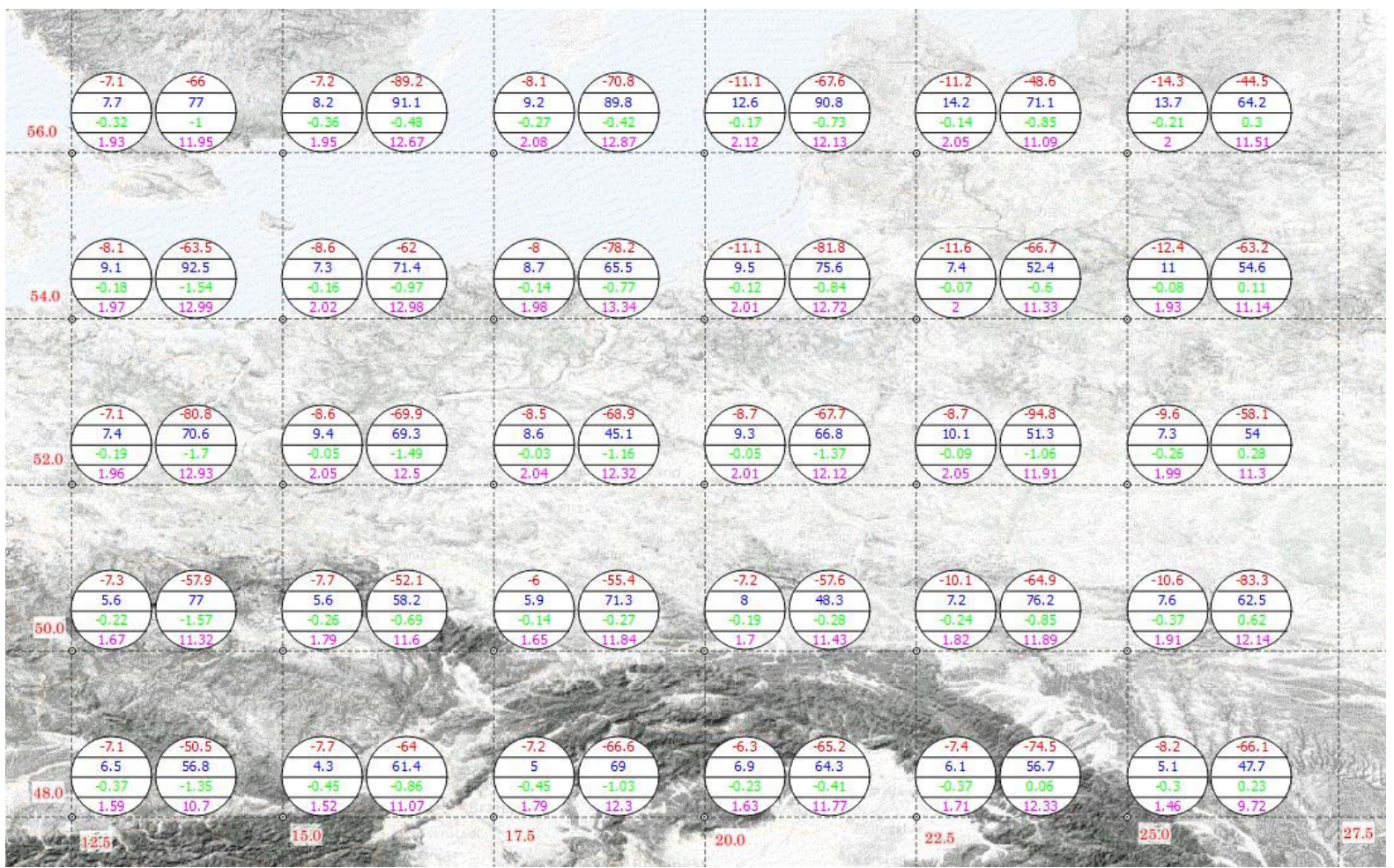

Fig. 5. Spatial distribution of basic statistics for hydrostatic (left circle) and wet (right circle) component in millimeters.

\subsection{COMPARISONS FOR THE WHOLE WORLD}

In this case, the aim was to see how the differences look like for the whole planet. To present the differences, four snapshots of four selected epochs (in February, May, August and November of 2013) were taken, separately for the dry and wet components (see Fig. 6). Looking through this figure, it can be stated that generally, the differences between predicted and final zenith tropospheric delays are about 10 times bigger for the wet component than for the dry. Range for the dry differences is $\pm 2 \mathrm{~cm}$, whilst for the wet differences the range is $\pm 20 \mathrm{~cm}$. In most cases the dry differences are between $\pm 5 \mathrm{~mm}$ and the wet differences fall between $\pm 5 \mathrm{~cm}$. The differences in both cases rarely reach their extreme values. The differences for the whole world are quite similar to those observed for the chosen cell as well as for the region of Central Europe, at least in most cases.

What seems to be very important, the values of differences for the wet delays are much more uncorrelated in space than the corresponding values of dry differences. The wet differences change rapidly from cell to cell. The corresponding values computed for dry component behave much more smoothly, the same colors on the plots create bigger clusters. It proves difficulties in spatial interpolation of the wet tropospheric delays, at least for the given resolution of the grid. 

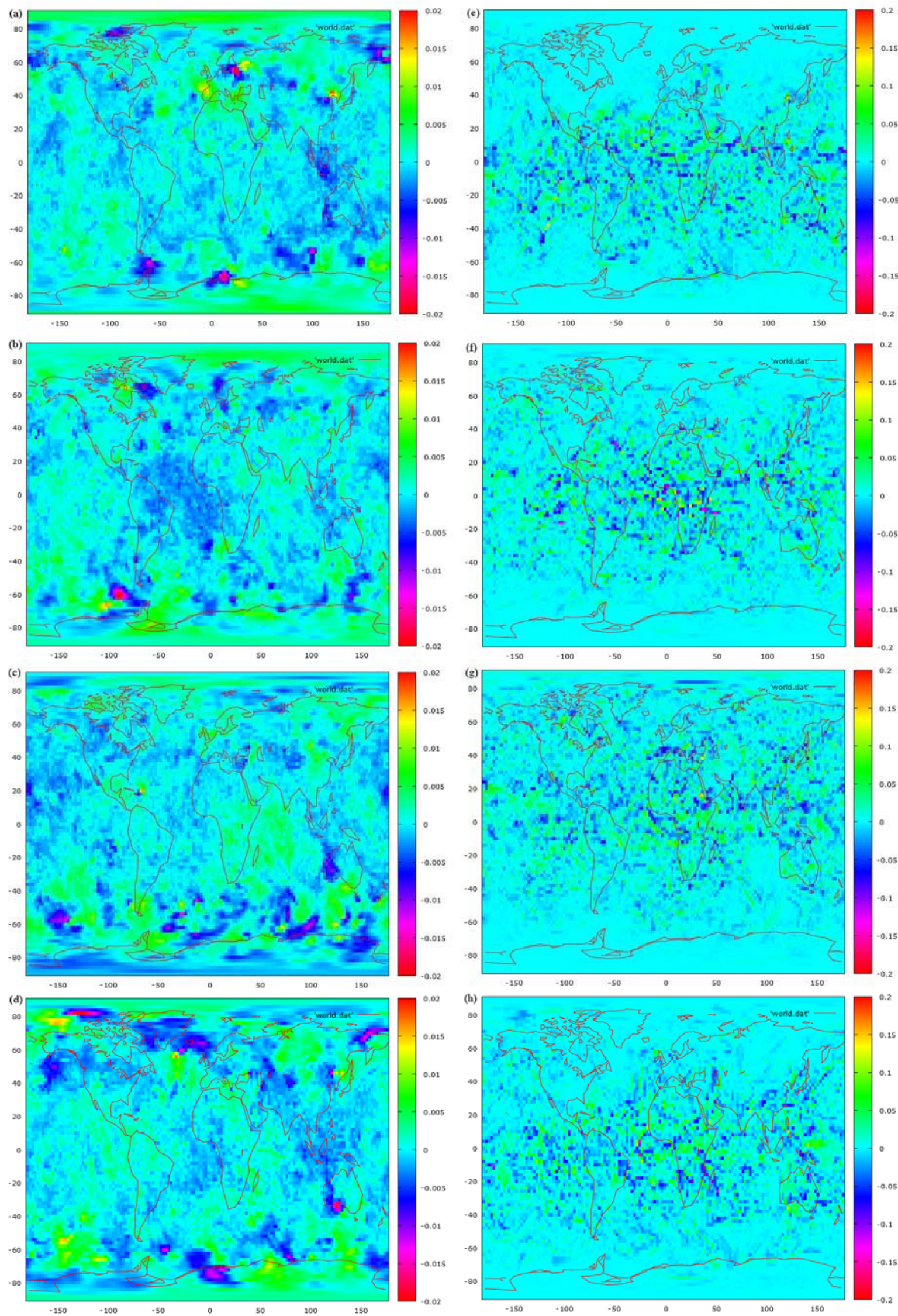

Fig. 6. Global distribution of predicted minus final zenith dry (a) and wet (b) delays in meters for 4 epochs during the year $(14.02 .2013,15.05 .2013,13.08 .2013$ and 11.11.2013; 18:00UT). 


\section{CONCLUSIONS AND DISCUSSION}

It is clearly seen from all the results that the dry delays are much easier to be predicted. The differences between the predicted and final zenith values do not exceed $10 \mathrm{~mm}$, for the cell located in the North-Eastern part of Poland (Fig. 2a, 3a). When looking at the whole region of the Central Europe, there are only 6 cells, generally located in Eastern part of the region, when the differences are separated by more than $\pm 10 \mathrm{~mm}$ from zero, never exceeding $15 \mathrm{~mm}$ (Fig. 5). For the whole world, with the four dates analysed, there are only a few cells with absolute values of differences reaching $20 \mathrm{~mm}$ (Fig. 6).

Wet delays are more difficult to be predicted - the differences for zenith values are within $\pm 5 \mathrm{~cm}$, with some rare cases (less than 10 for the total amount of about 1500 differences for the one cell) when they exceed these borders (Fig. 2b, 3b).

When analysing the delay for a non-zenith satellite, the resulting prediction error consists of an error in prediction of the zenith value and an error in prediction of the a coefficients included in mapping procedure (see Eqn. 2). Part of the dry error will be included in the estimated wet delay. In this case the most differences between the predicted and actual delays are contained within $\pm 5 \mathrm{~cm}$ for dry and $\pm 50 \mathrm{~cm}$ for wet components, when assumed that the elevation amounts to $5^{\circ}$. In case of $15^{\circ}$ elevation, the respective ranges can be estimated as $\pm 2 \mathrm{~cm}$ for dry and $\pm 15 \mathrm{~cm}$ for wet delay differences (Fig. 4a,b,c,d). The respective standard deviations are $2 \mathrm{~cm}$ and $12.9 \mathrm{~cm}$ for dry and wet components respectively. This analysis cumulates the zenith delay error and the error for the a coefficient occurring in Eqn. 2. The results show that current quality of the forecasting service raises question whether there may be any benefits while skipping the process of wet component estimation in real-time GNSS processing.

In the standard GNSS processing scheme, the hydrostatic zenith delay is held fixed and wet zenith delay is estimated. Both components are mapped to the satellite elevation angle according to the mapping function. In case of the analysed VMF1 model, the mapping corresponds to the Eqn. 2. The mapping coefficients for hydrostatic and wet components differ for low elevation angles and thus the error in the zenith hydrostatic delay cannot be fully absorbed into estimated zenith wet delay. The error described above is called hydrostatic/wet mapping separation error (Kouba, 2007). Thus the hydrostatic component accurate estimation plays important role in GNSS processing.

The wet parts temporal variability exceeds 6 hours resolution of the tropospheric data grids available at the service. In the example presented by Böhm et al. (2006) zenith wet delay obtained from the forecast weather model is compared against the value obtained using the VLBI technique. The results show errors up to $20 \mathrm{~mm}$. In addition, comparing the predicted and final data from the service, the zenith wet delay error can reach over $5 \mathrm{~cm}$. The wet component is the estimated parameter during the GNSS processing, and does not need to be known for processing periods longer than a few hours. In frames of real-time applications using the precise values of zenith wet delay, it can be useful for reducing the initiation times for positioning methods, like Precise Point Positioning PPP (Kouba, 2007). The quantitative analysis on how the predicted wet delay coefficients reduces the convergence time of GNSS positioning could be an area of further studies.

The aspect of how improved zenith wet delay influences accuracy and convergence time of real-time PPP was analysed by Shi et al. (2014). The research was based on transferring precise zenith wet delays from local augmentation system in real-time and fixing the wet delay instead of estimating it. Although, the parameters are acquired by means of different method of estimation optimal coefficients for local area second-order model, quality of the zenith wet delays is comparable to the VMF1 prediction (see Table 2), the RMS of the residuals for the used station is between 1 and $2 \mathrm{~cm}$. The hydrostatic zenith delay and 
mapping function are different, however the results show the range of improvement that may be expected for real-time PPP. Two cases, one with quiet and one with active troposphere condition, were analysed by the authors. For the former RMS horizontal accuracy after 20 minutes was improved from $13.2 \mathrm{~cm}$ to $9.2 \mathrm{~cm}$. The vertical RMS after 20 minutes improved from $18.3 \mathrm{~cm}$ to $10.1 \mathrm{~cm}$. Longer initialization times did not bring significant improvements. The accuracies during the active troposphere test case improved from $16.0 \mathrm{~cm}$ and $23.4 \mathrm{~cm}$ to $12.4 \mathrm{~cm}$ and $13 \mathrm{~cm}$ for horizontal and vertical components respectively.

Summarizing, the predicted values of the dry tropospheric delay component, both zenith and mapped, can be safely used in real time PPP applications, but on the other hand, while using the wet predicted values, one should be very careful.

\section{REFERENCES}

Böhm J., Schuh H. (2004) Vienna Mapping Functions in VLBI analyses, Geophysical Research Letters, Vol. 31, No. L01603, doi: 10.1029/2003GL018984.

Böhm J., Werl B., Schuh H. (2006) Troposphere mapping functions for GPS and VLBI from ECMWF operational analysis data, Journal of Geophysical Research, Vol. 111, No. B02406, doi: 10.1029/2005JB003629.

Böhm J., Schuh H. (2007) Troposphere gradients from the ECMWF in VLBI analysis, Journal of Geodesy, Vol. 81, No. 6-8, 403-408.

Böhm J., Kouba J., Schuh H. (2008) Forecast Vienna Mapping Functions 1 for real-time analysis of space geodetic observations, Journal of Geodesy, Vol. 83, No. 5, 397-401.

Chen Q., Song S., Zhu W. (2012) An Analysis for Accuracy of Tropospheric Zenith Delay Calculated from ECMWF/NCEP Data over Asia, Chinese Journal of Geophysics, Vol. 55 , No. 4, 275-283.

Davis J., Herring T., Shapiro A., Rogers E., Elgered G. (1985) Geodesy by Radio Interferometry: Effects of Atmospheric Modelling Errors on Estimates of Baseline Lenght, Radio Science, Vol. 20, No. 6, 1593-1607.

Herring T.A. (1992) Modelling atmospheric delays in the analysis of space geodetic data, Proceedings of the symposium refraction of transatmosphericsignals in geodesy, eds. de Munck JC, Spoelstra TAT., Hague, 157-164.

Ifadis I. (1986) The atmospheric delay of radio waves: Modeling the elevation dependence on a global scale, Technical Report 38L, Chalmers University of Technology, Gothenburg, Sweden.

Jin S., Park J.U., Cho J.H., Park P.H. (2007) Seasonal variability of GPS-derived zenith tropospheric delay (1994-2006) and climate implications, Journal of Geophysical Research, Vol. 112, No. D9, DOI: 10.1029/2006JD007772.

Marini J.W. (1972) Correction of satellite tracking data for an arbitrary tropospheric profile, Radio Science, Vol. 7, No. 2, 223 - 231.

Leick A. (1994) GPS Satellite Surveying, Wiley-Interscience Publication, New York.

Niell A.E. (1996) Global mapping functions for the atmosphere delay at radio wavelengths, Journal of Geophysical Research: Solid Earth, Vol. 101, No. B2, 3227-3246.

Nilsson T., Böhm J., Wijaya D.D., Tresch A., Nafisi V., Schuh H. (2013) Path Delays in the Neutral Atmosphere, Atmospheric Effects in Space Geodesy, Springer Verlag, eds. Böhm J., Schuh H., 73-136. 
Shi J., Xu C., Guo J., Gao Y. (2014) Local troposphere augmentation for real-time precise point positioning, Earth, Planets and Space, 2014, No. 66:30, doi:10.1186/1880-598166-30.

Urquhart L., Nievinski F., Santos M.C., (2014) Assessment of troposphere mapping functions using three-dimensional ray-tracing, GPS Solutions, Vol. 18, No. 3, 345-354, DOI 10.1007/s10291-013-0334-8.

Received: 2014-09-09,

Reviewed: 2014-10-07, by S. Oszczak,

Accepted: 2014-10-13. 